\title{
An Experimental Study of In-plane Oval Damper
}

\author{
Chien-Liang Lee ${ }^{1}$, Yen-Po Wang ${ }^{2}$, Meng-Yan Cai ${ }^{2}$ \\ ${ }^{1}$ School of Civil Engineering and Architecture, Xiamen University of Technology \\ No. 600, Ligong Road, Jimei District, Xiamen, China \\ cllee63@hotmail.com; ypwang@mail.nctu.edu.tw \\ ${ }^{2}$ Department of Civil Engineering, National Chiao-Tung University \\ No. 1001, University Road, Hsinchu, Republic of China \\ a2012212@gmail.com
}

\begin{abstract}
This paper presents a new type of seismic metallic yielding damper referred to as the in-plane oval damper (i-POD) which consists of two circular arches with intermediate straight arms in a closed-form. It is designed to deform inelastically in an in-plane flexural mode to dissipate seismic energy for building structures. A series of component tests of five i-PODs with various dimensions was conducted to assess their energy-dissipative characteristics (e.g. initial stiffness, post-yielding stiffness ratio, ultimate strength, ultimate displacement and ductility), which in turn serves as parametric study to gain more insight of this closed-form in-plane damper. Test results indicate that the hysteresis loops of all the dampers are full and consistently stable under cyclic loadings. Moreover, the iPOD effectively minimizes the problems of displacement setback and end rotation of its previous version, the in-plane arch-shaped damper, which would otherwise lead to loss of energy-dissipative capacity. Parametric study indicates that, in general, the i-POD with a shorter length of straight arms and a smaller radius of curvature of the circular arch exhibits a larger strength and better energydissipative capacity, but tolerates a smaller ultimate displacement as a trade-off. Furthermore, quadratic functions representing the mechanical parameters and energy-dissipative capacity of the dampers with respect to dimensionless design parameters have been proposed for design purpose, in particular at the preliminary design stage. Good correlations between the experimental results and regression formulae have been observed, suggesting that these empirical formulae can be adopted to determine the geometric dimensions of the i-POD for desired performance specifications in terms of ultimate strength, ultimate displacement or ductility.
\end{abstract}

Keywords: Seismic, Metallic Yielding Damper, In-Plane Oval Damper, Component Tests, Hysteresis Loops.

\section{Introduction}

Supplemental energy-dissipative dampers [1-3] have nowadays been widely implemented for seismic vibration control of both new and retrofitted building structures. As an effort to minimize material utilization and to achieve the desired ultimate strength, metallic yielding dampers (MYDs) designed to deform inelastically in an in-plane flexural mode have attracted extensive attentions recently, such as the steel damper in form of a simple portal frame with slots in the horizontal part [4], the steel slit dampers (SSD) [5-6], the comb-teeth damper (CTD) [7] and the "dual function" metallic damper (DFMD) [8] with single-rounded-hole or the double X-shaped steel plates. Wang et. al [9-12] also proposed an in-plane arch-shaped damper (Figure (1a)) to minimize the effects of stress concentration and warping of the in-plane portal frameshaped damper [10], and therefore to avoid premature failure. Hysteresis loops from the component tests under cyclic loads indicated consistent and stable energy-dissipative characteristics of the in-plane arch-shaped damper.

In this paper, a new type of MYD referred to as the in-plane oval damper (i-POD) [13-15] consisting of two circular arches with intermediate straight arms in a closed-form (Figure 2) is proposed to minimize the loss of energy-dissipative capacity of the in-plane arch-shaped damper (Figure (1b)) due to the slip between the pin and drilled hole in the steel plates. A series of component tests of five i-PODs with various dimensions has been conducted to assess their mechanical parameters (e.g. ultimate strength, ultimate displacement, initial stiffness, post-yielding stiffness ratio and ductility) and energy-dissipative capability (e.g. the enclosing area of the hysteresis loops). Based on the test results, the energydissipative performance and the suggestions for the geometric design of the i-POD are discussed. 

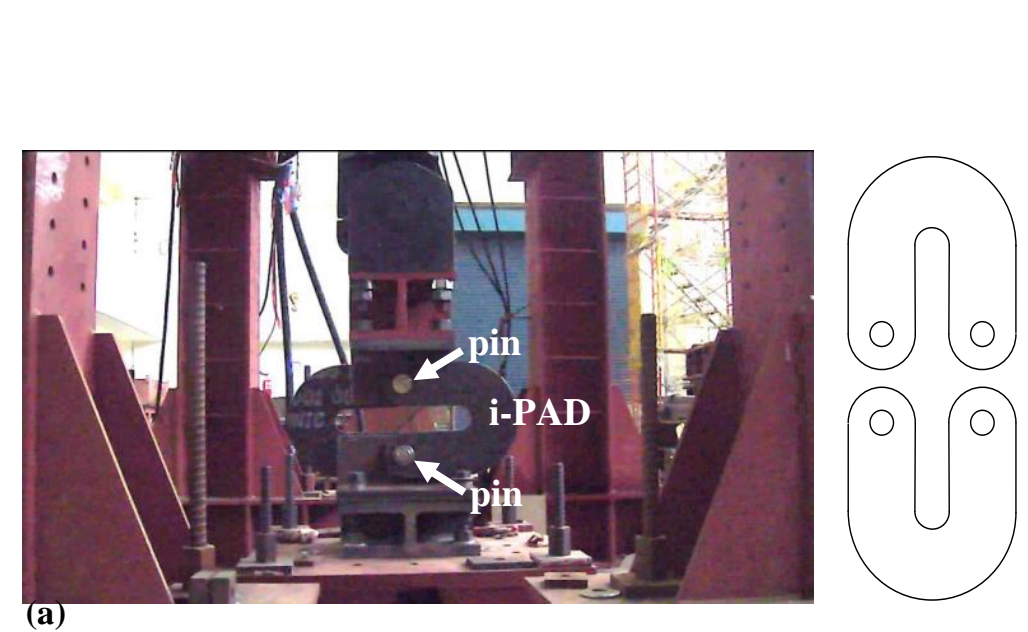

Fig. 1: In-plane arch-shaped damper: (a)

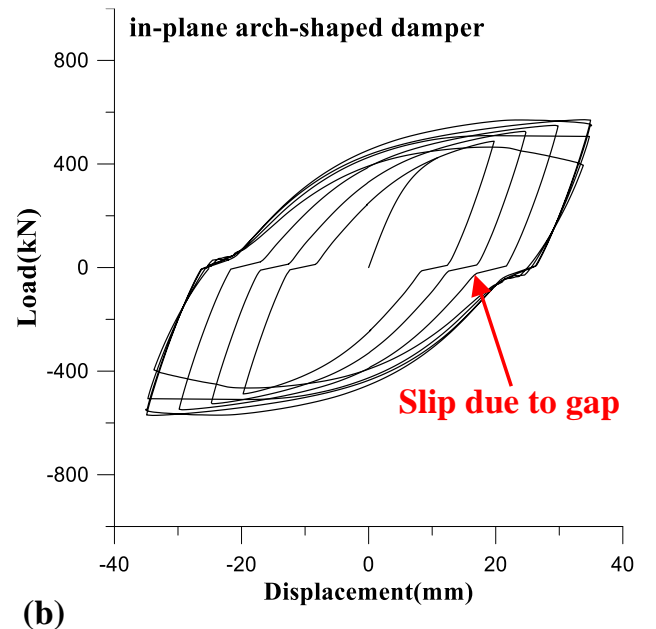

(b)

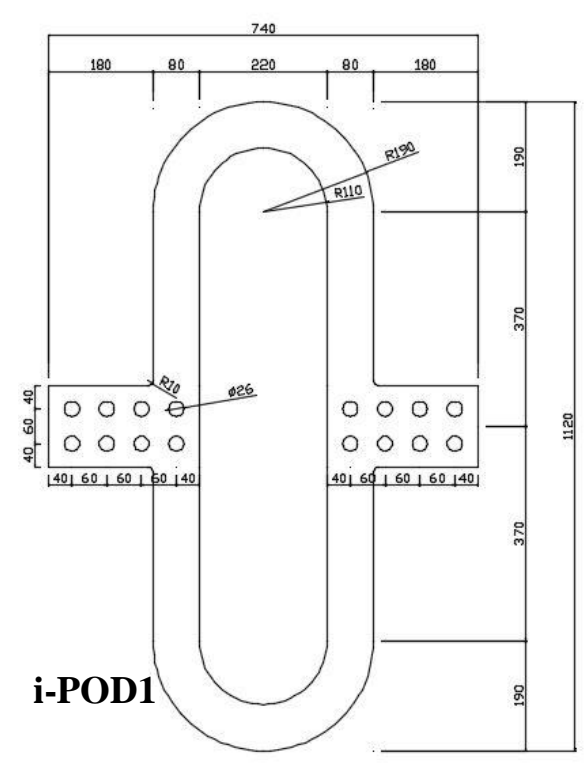

Fig. 2: Geometric dimensions of i-PODs [13].

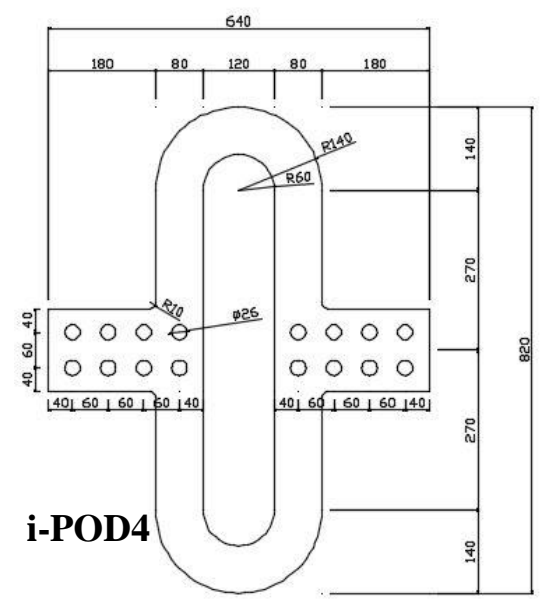

\section{Design of In-plane Oval Damper (i-POD)}

The i-POD consisting of two circular arches with intermediate straight arms in a closed-form cut from a steel plate is developed as shown in Figure 2 in which $R_{i}$ and $R_{o}$ are respectively the inner radius and the outer radius of the circular arches, $h=R_{o}-R_{i}$ and $l$ are respectively the depth of the cross section and half the length of the intermediate straight arms, and $t$ is the thickness of the steel plate. In order to know the nonlinear behavior of the proposed i-POD, a series of component tests for the dampers with various dimensions is conducted, and the energydissipative performance and mechanical parameters of the dampers are evaluated directly from the experimental results based on a bi-linear hysteretic model. 


\section{Component Tests}

\subsection{Damper Specimens}

Five i-PODs designed with different radiuses of curvature for the circular arches and various lengths for the intermediate straight arms were fabricated by using SN490B steel plates $(t=28 \mathrm{~mm})$ for component tests to compare their their energy-dissipative characteristics. Geometric dimensions of five i-PODs are summarized in Table 1 and only the design drawings of the i-POD1 and i-POD4 are shown in Figure 2 due to the length limitation of the paper. For the iPOD1, i-POD2 and i-POD3, they were designed to have the same radius of curvature for the circular arches (the average radius of $\left.R=\left(R_{i}+R_{o}\right) / 2=150 \mathrm{~mm}\right)$, but different lengths for the straight arms $(l=370 \mathrm{~mm}, 270 \mathrm{~mm}$ and $170 \mathrm{~mm})$, while for the i-POD-2, i-POD4 and i-POD5, they were designed to have the same length for the straight arms $(l=270$ $\mathrm{mm})$, but different radiuses of curvature for the circular arches $(R=150 \mathrm{~mm}, 100 \mathrm{~mm}$ and $200 \mathrm{~mm})$.

Table 1: Dimensions of the i-POD for component tests (unit: $\mathrm{mm}$ ).

\begin{tabular}{|c|c|c|c|c|c|c|}
\hline Specimen & $R_{i}$ & $R_{o}$ & $h=R_{o}-R_{i}$ & $l$ & $t$ & $\phi$ \\
\hline \hline i-POD1 & 110 & 190 & 80 & 370 & 28 & 26 \\
\hline i-POD2 & 110 & 190 & 80 & 270 & 28 & 26 \\
\hline i-POD3 & 110 & 190 & 80 & 170 & 28 & 26 \\
\hline i-POD4 & 60 & 140 & 80 & 270 & 28 & 26 \\
\hline i-POD5 & 160 & 240 & 80 & 270 & 28 & 26 \\
\hline
\end{tabular}

\subsection{Experimental Setup}

The damper specimens were connected with bolts through the T-shaped fixtures to the 100-ton actuator in one end and to the strong floor in the other, as shown in Figure 3. Cyclic sinusoidal loadings with strokes of $2 \mathrm{~mm}, 5 \mathrm{~mm}, 7 \mathrm{~mm}, 10$ $\mathrm{mm}, 15 \mathrm{~mm}, 20 \mathrm{~mm}, 25 \mathrm{~mm}, 30 \mathrm{~mm}, 35 \mathrm{~mm}$ and $40 \mathrm{~mm}$, repeated 5 cycles each in sequence, were conducted at a loading rate of $0.05 \mathrm{~Hz}$ for each i-POD.

As an effort to assess the mechanical and energy-dissipative characteristics of the i-POD, an idealized bi-linear model is introduced to define the inelastic force-displacement relationship of the damper, as shown in Figure 4 . The initial stiffness $\left(K_{1}\right)$, post-yielding stiffness $\left(K_{2}\right)$, post-yielding stiffness ratio $\left(\alpha=K_{2} / K_{1}\right.$ ), effective yielding displacement ( $\left.\Delta_{y}^{e f f}\right)$, effective yielding strength $\left(P_{y}^{e f f}=K_{1} \Delta_{y}^{e f f}\right)$, ultimate displacement $\left(\Delta_{u}\right)$, ultimate strength $\left(P_{u}\right)$ and ductility ( $\mu=\Delta_{u} / \Delta_{y}^{e f f}$ ) are to be determined directly from the test results. It is noted that the effective yielding displacement and effective yielding strength are defined as the coordinates at the intersection of the two slopes representing the initial and post-yielding stiffness, as indicated in Figure 4. Moreover, the ultimate displacement $\left(\Delta_{u}\right)$ refers to the maximum deformation of the damper at which its strength starts to deteriorate after the first cycle of loading observed in the test, and the maximum force of the damper corresponding to this ultimate displacement is referred to as the ultimate strength $\left(P_{u}\right)$.

\subsection{Experimental Results and Discussion}

Test results of i-PODs in terms of hysteresis loops are illustrated in Figures 5(a) to 5(c) which indicate that the hysteresis loops of all the dampers are full and consistently stable under cyclic loadings until the amplitude where the ultimate strength has been achieved in the first cycle and decays afterwards. It should be noted that due to the length limitation of the paper, only the results of three i-PODs (i-POD1, i-POD3 and i-POD4) are presented herein. Moreover, the loss of energy-dissipative capacity of the in-plane arch-shaped damper due to the problems of slip and end rotation (Figure 1(b)) has been effectively improved by the proposed i-POD (Figure 5) connected to the T-joints as fixed ends by using bolts (Figure 3) at which the rotations of the straight arms are inherently eliminated due to the symmetry of the i-POD. 


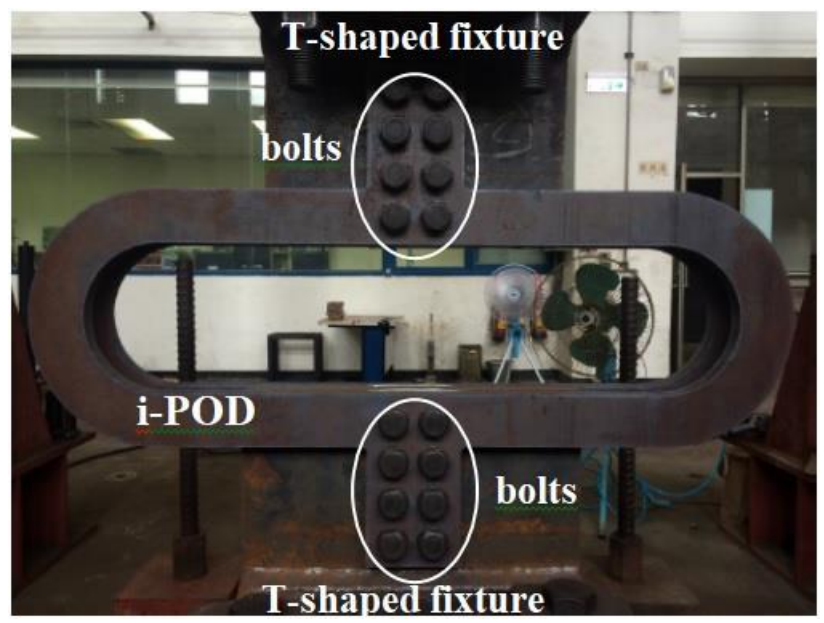

Fig. 3: Experimental setup for component tests

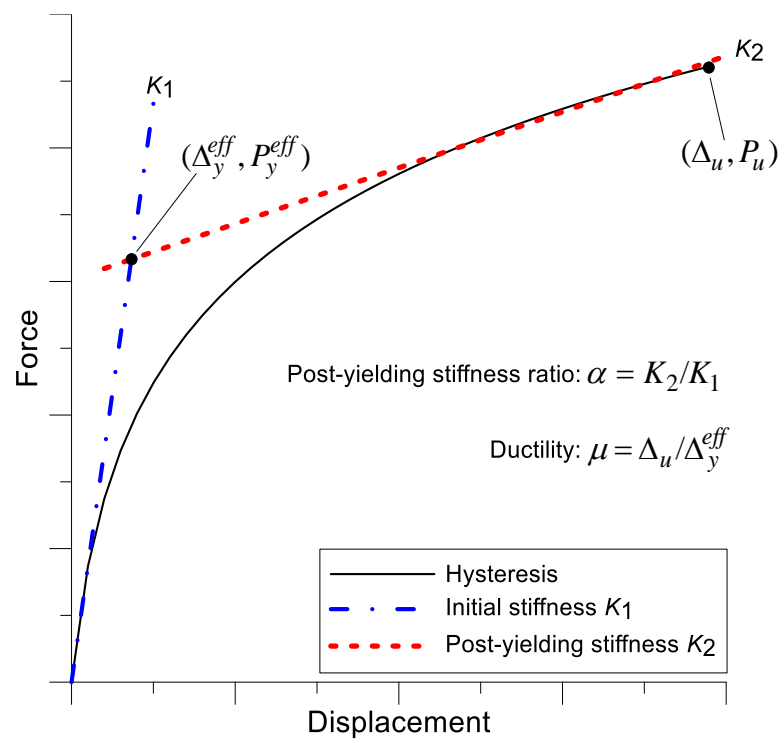

Fig. 4: Bi-linear hysteretic model for the i-POD.

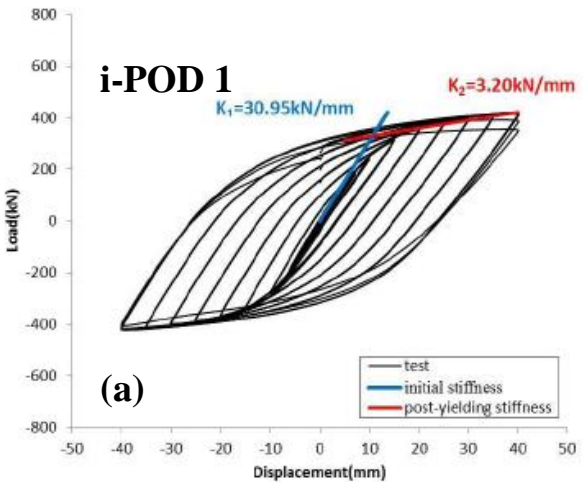

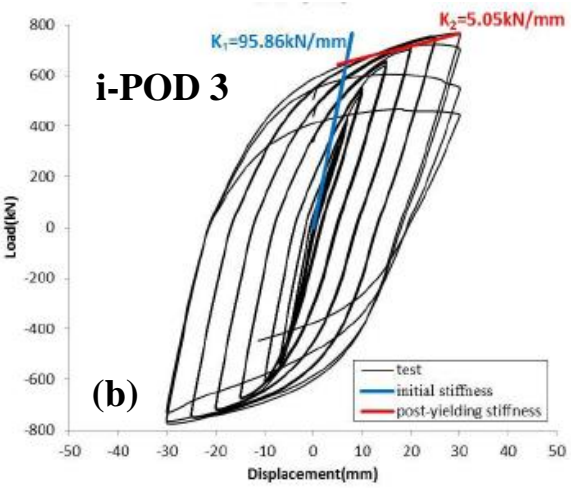

Fig. 5: Hysteresis loops of i-PODs [13].

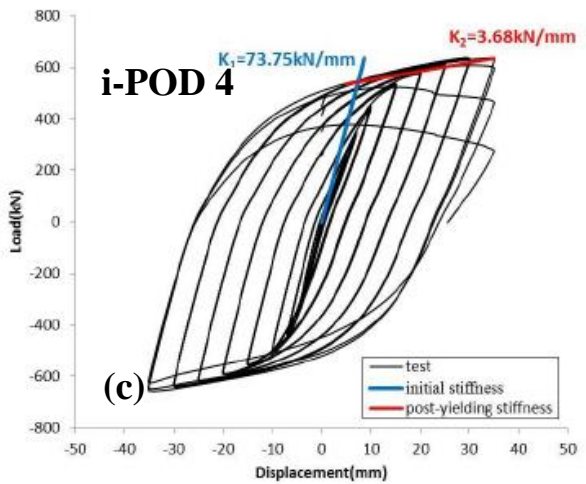


(a) ultimate displacement, ultimate strength and energy-dissipative capability

The ultimate strength $\left(P_{u}\right)$ and the enclosing area $\left(A_{H}\right)$ or the energy-dissipative capacity of the hysteresis loops corresponding to the ultimate displacement $\left(\Delta_{u}\right)$ of each i-POD are summarized in Table 2. Taking the results of the iPOD1 as an example, when the loading amplitude is $40 \mathrm{~mm}$, the i-POD1 reaches its ultimate strength of $P_{u}=421 \mathrm{kN}$ and the maximum value of $A_{H}=49197 \mathrm{kN}-\mathrm{mm}$ at the first cycle and deteriorates with declining strength afterwards due to cracking at the bottom right location (near to the connection joint) of the i-POD1, as shown in Figure 6(a). It is noted that the amplitude of $40 \mathrm{~mm}$ at which the maximum force of the i-POD1 starts to deteriorate is referred as the ultimate displacement $\left(\Delta_{u}=40 \mathrm{~mm}\right)$ in this study. Among these damper specimens, the i-POD1 and i-POD5 sustained the largest ultimate displacement with $\Delta_{u}=40 \mathrm{~mm}$, followed by the i-POD2 and i-POD4 with $\Delta_{u}=35 \mathrm{~mm}$, and the i-POD3 sustained the lowest displacement with $\Delta_{u}=30 \mathrm{~mm}$.
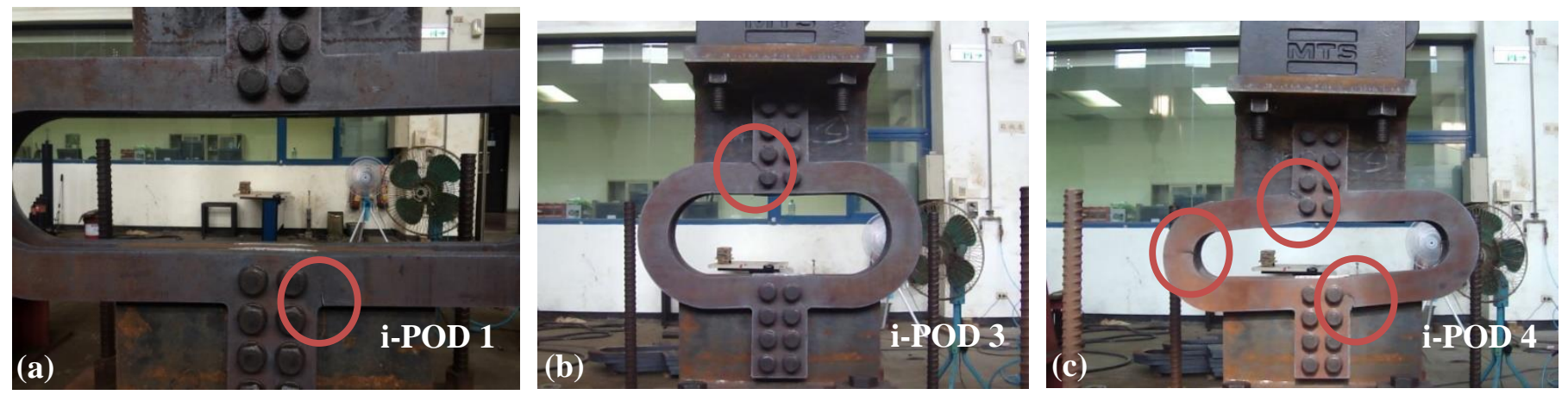

Fig. 6: Cracking locations of i-PODs at the ultimate states [13].

Table 2: Summary of the component test results.

\begin{tabular}{|c|c|c|c|c|c|}
\hline Parameters & i-POD1 & i-POD2 & i-POD3 & i-POD4 & i-POD5 \\
\hline$R=\left(R_{i}+R_{o}\right) / 2(\mathrm{~mm})$ & 150 & 150 & 150 & 100 & 200 \\
\hline$l(\mathrm{~mm})$ & 370 & 270 & 170 & 270 & 270 \\
\hline$l R\left(\mathrm{~mm}^{2}\right)$ & 55500 & 40500 & 25500 & 27000 & 54000 \\
\hline$K_{1}(\mathrm{kN} / \mathrm{mm})$ & 30.95 & 52.49 & 95.86 & 73.75 & 38.37 \\
\hline$K_{2}(\mathrm{kN} / \mathrm{mm})$ & 3.20 & 4.80 & 5.05 & 3.68 & 3.00 \\
\hline$\xi=(l R) /(h t)$ & 24.78 & 18.08 & 11.38 & 12.05 & 24.11 \\
\hline$\alpha=K_{2} / K_{1}$ & 0.103 & 0.091 & 0.053 & 0.050 & 0.078 \\
\hline$\Delta_{y}^{e f f}(\mathrm{~mm})$ & 10.38 & 8.19 & 6.81 & 7.38 & 9.74 \\
\hline$P_{y}^{e f f}(\mathrm{kN})$ & 321 & 430 & 653 & 544 & 374 \\
\hline$\Delta_{u}(\mathrm{~mm})$ & 40 & 35 & 30 & 35 & 40 \\
\hline$P_{u}(\mathrm{kN})$ & 421 & 545 & 765 & 637 & 458 \\
\hline$\mu=\Delta_{u} / \Delta_{y}^{\text {eff }}$ & 3.85 & 4.27 & 4.41 & 4.74 & 4.11 \\
\hline$A_{H}(\mathrm{kN}-\mathrm{mm})$ & 49197 & 53523 & 69533 & 71515 & 56401 \\
\hline$\left.V_{M}(\mathrm{~mm})^{3}\right)$ & 23206400 & 19062400 & 14918400 & 14694400 & 23990400 \\
\hline$A_{H} / V_{M}\left(\mathrm{kN} / \mathrm{mm}^{2}\right)$ & 0.00212 & 0.00281 & 0.00466 & 0.00487 & 0.00235 \\
\hline
\end{tabular}


As far as the energy-dissipative capacity is concerned, the i-POD4 dissipated the largest energy $\left(A_{H}\right)$, followed by the i-POD3, and the i-POD1 dissipated the lowest, while the i-POD3 possessed the largest ultimate strength $\left(P_{u}=\right.$ $765 \mathrm{kN})$, followed by the i-POD4 $\left(P_{u}=637 \mathrm{kN}\right)$, and the i-POD1 possessed the lowest $\left(P_{u}=421 \mathrm{kN}\right)$. Moreover, the ultimate displacements of the i-PODs corresponding to their ultimate strengths fall within $\Delta_{u}=30 \mathrm{~mm}$ (i-POD3) and $\Delta_{u}=40 \mathrm{~mm}$ (i-POD1 and i-POD5). The cracking locations of i-PODs at the ultimate states are shown in Figures 6(a) to 6(c) in which only one crack occurred at the top or bottom straight arms near to the connection joints, such as the iPOD1and i-POD3, while three cracks were observed for the i-POD4 at both the top and bottom straight arms and at the inner central location of the left circular arch (Figure 6(c)). The results indicate that the yielding area of the iPOD4 seems to be more widely spread to allow for an enhanced energy-dissipative capability as revealed from its largest $A_{H}$ of the hysteresis loops before initiation of cracks.

(b) mechanical parameters of a bi-linear hysteretic model

Taking the mechanical parameters of the i-POD1 obtained according to the definitions depicted in Figure 4 as an example, the initial stiffness can be read, from the experimental hysteresis loops (Figure 5(a)), to be $K_{1}=30.95$ $\mathrm{kN} / \mathrm{mm}$, the post-yielding stiffness determined as $K_{2}=3.20 \mathrm{kN} / \mathrm{mm}$, the corresponding post-yielding stiffness ratio computed accordingly to be $\alpha=K_{2} / K_{1}=0.103$, the effective yielding displacement of $\Delta_{y}^{e f f}=10.38 \mathrm{~mm}$ and the effective yielding strength of $P_{y}^{e f f}=K_{1} \Delta_{y}^{e f f}=321 \mathrm{kN}$ obtained from the coordinates at the intersection of the two slopes corresponding to the initial and post-yielding stiffness. Moreover, the ultimate displacement of the i-POD1 obtained as $\Delta_{u}=40 \mathrm{~mm}$ (corresponding to $P_{u}=421 \mathrm{kN}$ ) was in turn used to estimate the ductility to be $\mu=\Delta_{u} / \Delta_{y}^{e f f}=$ $40 / 10.38=3.85$.

(c) regression formulae for representing the mechanical parameters in terms of $\xi=(l R) / h t$

The mechanical parameters of all i-PODs determined from the experiments are summarized in Table 2. It should be noted that the dissipated energy per unit volume of the consumption of the steel material $\left(A_{H} / V_{M}\right)$ at the ultimate states are also included in Table 2 for comparison. Results indicate that, in general, the i-POD designed with a shorter length $(l)$ of straight arms and a smaller radius $(R)$ of curvature of the circular arch exhibits the larger ultimate strength ( $P_{u}=765 \mathrm{kN}$, i-POD3), initial stiffness ( $K_{1}=95.86 \mathrm{kN} / \mathrm{mm}$, i-POD3), ductility ( $\mu=4.74$, i-POD4) and better energy-dissipative capacity ( $A_{H}=71515 \mathrm{kN}-\mathrm{mm}$, i-POD4), but tolerates a smaller ultimate displacement of $\Delta_{u}=30$ $\mathrm{mm}$ (i-POD3) or $35 \mathrm{~mm}$ (i-POD2 and i-POD4) as a trade-off. Moreover, observations of the results presented in Table 2 show that the value of $\alpha$ varies within 0.05 to 0.10 and the trend of $A_{H} / V_{M}$ is inversely proportional to $l R$, i.e. the smaller the value of $l R$, the better the efficiency of the consumption of the steel material.

In order to describe the mechanical characteristics (e.g. the strength-oriented parameters: $K_{1}, \alpha$, and $P_{u}$, and the displacement-oriented ones: $\Delta_{u}$ and $\mu$ ) and the energy-dissipative performance (e.g. $A_{H}$ ) of the i-PODs with their corresponding geometric design, a series of best-fitting quadratic functions (or the second-order polynomial functions) representing the mechanical parameters with respect to a dimensionless design parameter, $\xi=(l R) /(h t)$, are determined by using the experimental results through regression analyses. The regression curves or formulae together with the experimental data points tabulated in Table 2 are shown in Figures 7(a) to 7(f) in which good correlations between the experimental results and regression curves have been achieved. These proposed empirical formulae are very useful and can be adopted at the preliminary stage to determine the geometric dimensions of the i-POD for desired performance specifications in terms of ultimate strength, ultimate displacement or ductility (e.g. $P_{u}, \Delta_{u}$ or $\mu$ ) .

The parameters, $K_{1}$ and $P_{u}$, decrease quadratically (concave upward) with $\xi$ considered between 10 and 25 , while those of $\Delta_{u}$, on the contrary, increase quadratically (concave upward) with $\xi$. The regression curve of $\alpha$ is like 
a parabola opening downward (i.e. $\alpha$ tends to increase before the vertex at around $\xi=22.5$, and to decrease after the vertex), and this empirical formula can be used to estimate the value of $\alpha$ that is a necessary parameter commonly adopted adopted in a bi-linear hysteretic model for the nonlinear numerical analysis at the preliminary design stage, but it is not known in prior when designing a new damper. Similar to the parameters, $K_{1}$ and $P_{u}$, the trend of the ductility $(\mu)$ decreases quadratically with $\xi$, but its direction of the concave curve is downward. Moreover, the regression curve of $A_{H}$ varies with $\xi$ as a parabolas opening upward in which $A_{H}$ decrease with $\xi$ before the vertex (or the minimum value) at $\xi=22.5$ and afterwards tends to increase.
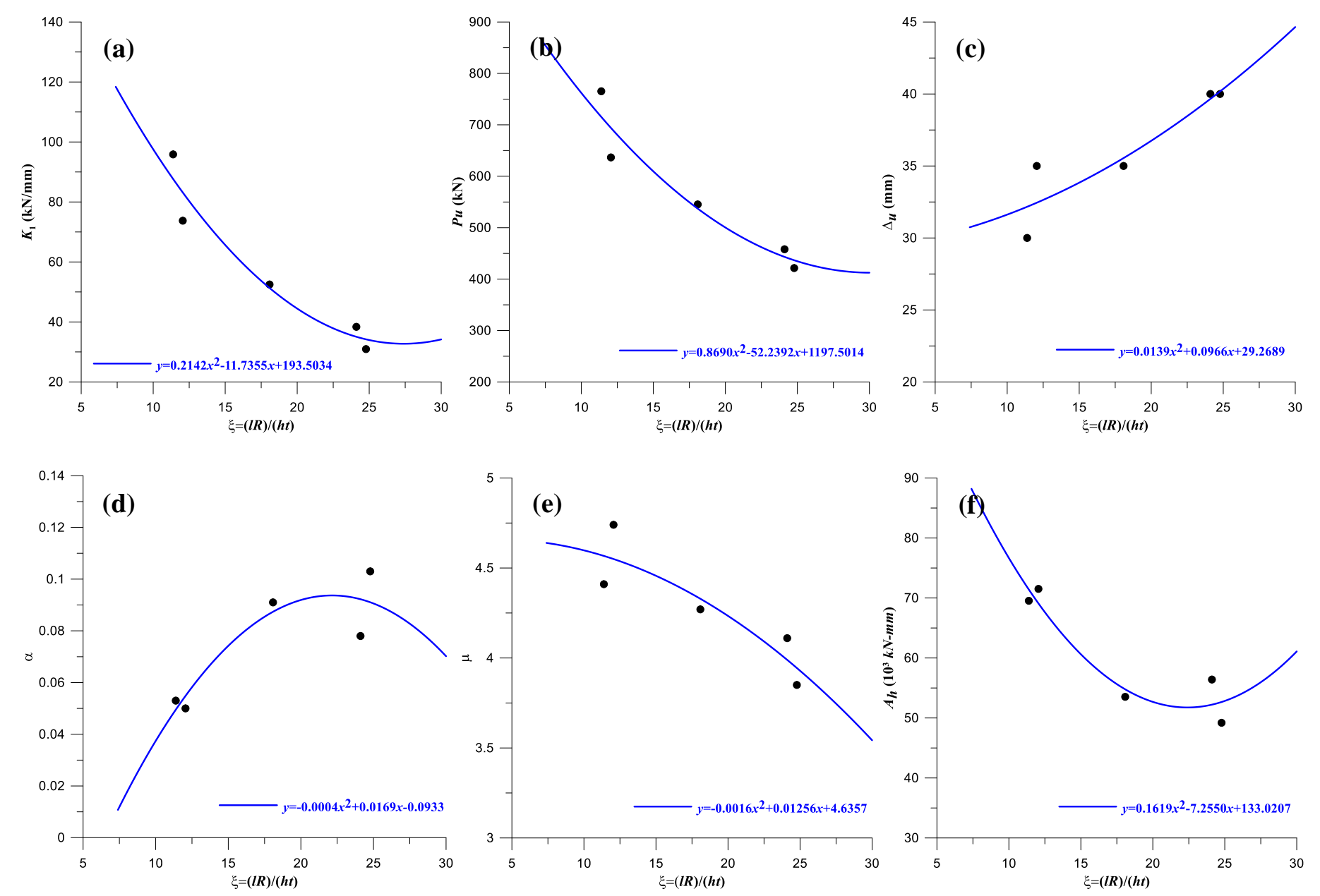

Fig. 7: Regression curves representing the mechanical characteristics of i-POD by a dimensionless design parameter.

\section{Conclusion}

In this paper, the in-plane oval damper (i-POD) cut from a steel plate in a closed-form with two circular arches and intermediate straight arms to enhance the energy-dissipative capacity of its previous version, the in-plane arch-shaped damper, has been proposed. A series of component tests of five i-PODs designed with different geometric dimensions has been conducted and compared with each other. All the hysteresis loops of i-PODs obtained from the component tests under cyclic loadings indicate consistent and stable energy-dissipative characteristics until the amplitude where the ultimate strength has been achieved. The full hysteresis loops of the proposed i-POD also reveal that the problems of displacement 
setback and end rotation of the in-plane arch-shaped damper has been effectively improved. Moreover, good correlations between the experimental results and regression formulae with respect to a proposed dimensionless design parameter $(\xi)$ have been observed, suggesting that these empirical formulae can be adopted to determine the geometric dimensions of the i-POD for desired performance specifications in terms of ultimate strength, ultimate displacement or ductility. However, the five i-PODs considered in this study are made of the same steel material and the same depth of the cross section and thickness of steel plates; therefore, more component tests of the i-POD with various steel material (strength) and different depth of the cross section and thickness of steel plates are suggested to conduct to obtain the more generalized formulae to predict the mechanical characteristics and energy-dissipative performance of the i-POD for further practical use in seismic vibration control of building structures.

\section{Acknowledgements}

This work is supported by the National Science Council of Republic of China under contract MOST 103-2625-M009-014, the Fujian Provincial Department of Science \& Technology (Project No. 2017J01495) and Xiamen University of Technology (Project No. YKJ17008R), China.

\section{References}

[1] T. T. Soong and G. F. Dargush, Passive Energy Dissipation Systems in Structural Engineering. New York: John Wiley \& Sons, 1997.

[2] T. T. Soong and B. F. Spencer Jr, "Supplemental energy dissipation: state-of-the-art and state-of-the-practice," Eng. Struct., vol. 24, no. 3, pp. 243-259, 2002.

[3] M. D. Symans, F. A. Charney, A. S. Whittaker, M. C. Constantinou, C. A. Kircher, M. W. Johnson and R. J. McNamara, "Energy dissipation systems for seismic applications: current practice and recent development," $J$. Struct. Eng., vol. 134, no. 1, pp. 3-21, 2008.

[4] J. H. Park and K. H. Lee, "Cyclic loading tests of steel dampers utilizing flexure-analogy deformation," The 15th World Conference on Earthquake Engineering, Lisbon, Portugal, 2012.

[5] R. W. K. Chan and F. Albermani, "Experimental study of steel slit damper for passive energy dissipation," Eng. Struct., vol. 30, no. 4, pp. 1058-1066, 2008.

[6] J. Zheng, A. Q. Li and T. Guo, "Analytical and experimental study on mild steel dampers with non-uniform vertical slits," Earthq. Eng. Eng. Vib., vol. 14, no. 1, pp. 111-123, 2015.

[7] S. Garivani, A. A. Aghakouchak and S. Shahbeyk, "Numerical and experimental study of comb-teeth metallic yielding dampers," Int. J. Steel Struct., vol. 16, no. 1, pp. 177-196, 2016.

[8] G. Li and H. N. Li, "Earthquake-resistant design of RC frame with dual functions metallic dampers," The 14th World Conference on Earthquake Engineering, Beijing, China, 2008.

[9] Y. P. Wang, D. H. Chen and C. L. Lee, "An experimental study of in-plane arch-shaped flexural damper," The 8th International Conference in Structural Engineering and Construction (ISEC-8), Sydney, Australia, 2015, pp. 293298.

[10] W. Y. Wang, "Mechanics of material and testing of in-plane arched damper," M.S. Thesis, Dept. Civ. Eng., National Chiao-Tung Univ., Hsinchu, Taiwan, 2014. (in Chinese)

[11] C. L. Lee, Y. P. Wang and M. Y. Cai, "An experimental study of in-plane arch-shaped damper," Earthq. Eng. Eng. Vib., 2017.

[12] C. L. Lee, Y. P. Wang YP and M. Y. Cai, "An experimental verification of seismic structural control using in-plane metallic damper," 3rd International Conference on Architecture, Material and Construction, (ICAMC 2017), Amsterdam, Netherlands, 2017.

[13] S. C. Huang, "Inelastic stress analysis of curved beams under bending and shear coupling, Master thesis," M.S. Thesis, Dept. Civ. Eng., National Chiao-Tung Univ., Hsinchu, Taiwan, 2016. (in Chinese) 
[14] Y. P. Wang, C. L. Lee and S. C. Huang, "Inelastic stress analysis of curved beams with bending and shear coupling," Proceedings of the World Congress on Civil, Structural, and Environmental Engineering (CSEE'16), Prague, Czech Republic, 2016.

[15] M. C. Tu, "Design and test of in-plane flexural dampers in a closed-form. Master thesis," Dept. Civ. Eng., National Chiao-Tung Univ., Hsinchu, Taiwan, 2017. (in Chinese) 